\title{
Potensi Penggunaan Kinect sebagai Alat Motion Capture untuk Animasi Karakter Digital
}

\author{
Aristarchus Pranayama Kuntjara ${ }^{1 *}$, Erandaru ${ }^{2}$, Tommy Gunawan ${ }^{3}$, Christian Hensel ${ }^{4}$ \\ 1,2 International Program in Digital Media, Fakultas Seni dan Desain, \\ Universitas Kristen Petra, Jl. Siwalankerto 121-131, Surabaya \\ 3,4 Program Studi Desain Komunikasi Visual, Fakultas Seni dan Desain, \\ Universitas Kristen Petra, Jl. Siwalankerto 121-131, Surabaya \\ *Penulis korespondensi; E-mail: arispk@petra.ac.id
}

\begin{abstract}
Abstrak
Kinect merupakan perangkat sensor motion capture yang mulanya dipakai untuk video game controller, tapi kini digunakan untuk berbagai macam keperluan yang membutuhkan sensor gerak. Kinect relatif murah dan mudah untuk didapatkan dan dipakai sebagai motion capture untuk menggerakkan karakter digital 3D. Dalam penelitian ini, uji coba dilakukan terhadap kemampuan Kinect dalam set-up sistem motion capture yang sesederhana mungkin dan mudah untuk dapat diakses oleh awam. Dari hasil uji coba didapatkan hasil dan saran atau anjuran pemakaian dan set-up yang paling efektif untuk dapat menggerakkan sebuah karakter digital 3D. Diharapkan hasil ini dapat mendorong penggunaan potensi Kinect lebih maksimal.
\end{abstract}

Kata kunci: Kinect, motion capture, karakter digital, 3D.

\begin{abstract}
Kinect is a motion capture sensor device that was originally used for video game controllers, but is now used for various purposes requiring motion sensors. Kinect is relatively cheap and easy to obtain and use as motion capture to move $3 D$ digital characters. In this study, trials were carried out on the ability of Kinect to set-up a motion capture system that was as simple as possible and generally easily accessible. The test results obtained showed the most effective results and suggestions or use and set-up to be able to move a $3 D$ digital character. It is hoped that these results can help in maximizing Kinect's potential in its use.
\end{abstract}

Keywords: Kinect, motion capture, digital character, 3D.

\section{Pendahuluan}

Pada tahun 2010, Microsoft memproduksi suatu perangkat sensor gerak bernama Kinect. Kinect memudahkan sebuah sistem komputer untuk menangkap gerak-isyarat penggunanya, yang berguna sebagai media interaksi manusia dengan sistem komputer, yang pada saat itu dijual sebagai perangkat tambahan untuk video game console Xbox 360. Dengan harga Kinect yang relatif jauh lebih murah dibandingkan dengan teknologi sensor serupa, memungkinkan bagi pengguna awam untuk memanfaatkannya untuk kebutuhan motioncapture yang dapat membantu pengguna menganimasikan sebuah karakter digital 3dimensi dengan cepat dan mudah.

Sementara pada industri animasi papan atas, teknologi motion capture biasanya menggunakan marker-based yang dipakai atau di- pasangkan pada tubuh manusia, dan ini sangat sulit dan mahal untuk didapatkan dan digunakan sehari-hari. Kinect ditawarkan pada pasar sebagai solusi biaya rendah, sensor markerless motion capture, untuk menjadi solusi dari mahalnya dan kompleksitas penggunaan high-end motion capture systems yang memiliki performa akurasi tinggi (Bilesan et al., 2019).

Bentuk animasi yang paling sering diperlukan dan paling sulit untuk diperoleh oleh content creator adalah animasi karakter digital 3dimensi. Konten digital dengan sebuah karakter yang dapat bergerak memungkinkan untuk menyampaikan pesan dengan tambahan unsur bahasa gerak tubuh yang lebih efektif. Dengan adanya karakter 3D yang dapat selalu dianimasikan dengan mudah, akan menambah kemampuan kreator dalam menciptakan konten-konten yang lebih atraktif dan komunikatif. 
Animasi dalam proses edukasi merupakan alat yang sangat berpengaruh pada keefektifan penyampaian suatu materi atau konten. Namun pada prakteknya, penerapan animasi sering terkendala oleh proses yang sulit, biaya yang mahal, dan memakan waktu lama, yang tidak sebanding dengan jangka waktu dan materi yang ingin disampaikan. Akhirnya proses animasi tersebut dilewatkan dan digantikan dengan metode yang tidak seefektif dengan animasi. Proses animasi yang sering diperlukan oleh pendidik awam yang sekaligus content creator perlu dibuat lebih mudah diakses oleh mereka agar potensi efektifitas materi yang ingin disampaikan dapat ditingkatkan. Kinect ini juga dapat diaplikasikan untuk suatu pertunjukan real-time dengan virtual character yang dikontrol oleh gerakan kita (Vera, et al., 2011). Potensi-potensi ini yang perlu kita teliti dan ungkap agar dapat dimanfaatkan semaksimal mungkin.

Tujuan dari penelitian ini adalah meneliti potensi atau bisa tidaknya dan keterbatasan, serta mencari sistem set-up yang paling optimal pada Kinect untuk digunakan sebagai motion capture yang tidak mahal dan sederhana untuk menganimasikan karakter digital 3-dimensi bagi pengguna umum dalam menciptakan konten edukasi. Penelitian awal ini terfokus pada kemampuan dan karakteristik Kinect, namun dapat juga memberi pertimbangan pada software, hardware, dan subyek atau model penggerak, serta gerakan, agar keseluruhan sistem dapat menjadi sistem motion capture yang efektif. Hasil dari penelitian akan memberikan manfaat berupa rekomendasi mengenai hal-hal apa saja yang perlu diperhatikan dan saran penggunaan dari set up sistem tersebut.

\section{Alat}

Kinect yang digunakan merupakan Kinect 2 for Windows. Kinect merupakan perangkat sensor tambahan untuk video game console Xbox 360 buatan Microsoft. Perangkat ini memampukan console atau sebuah gaming system untuk mendeteksi dan merekam gerakan pemain atau pengguna yang ada di depannya secara 3dimensi. Hal ini memungkinkan pengguna berinteraksi dengan gaming system tanpa hand-held controller pada umumnya. Kinect dapat mengenali gerak-isyarat tubuh, wajah, tangan, serta perintah suara dari pengguna. Pendeteksi gerak-isyarat dilakukan oleh "depth camera" yang terdiri dari proyektor laser infra- merah dan kamera video infra-merah pada bagian sensor perangkat (lihat Gambar 1).

Sistem Kinect menggunakan kamera inframerah untuk mendeteksi pola bintik-bintik yang terproyeksikan pada benda yang terlihat pada bidang pandang kamera. Kinect mampu membuat mapping benda-benda tersebut secara 3-dimensi dengan cara mengukur deformasi dari pola bintik tersebut. Perangkat juga memiliki sensor kamera video warna yang mendeteksi dan menentukan mapping kedalaman (depth). Terdapat juga mikrofon untuk mendeteksi suara. Teknologi ini dikembangkan oleh PrimeSense, Israel (Freedman et al., Shpunt, Spektor et. Al, 2010 dalam Dutta, 2011). Dengan menggunakan Kinect, kita dapat merekam gerakan tubuh manusia tanpa "marker" atau titik-titik penanda pada tubuh model yang melakukan gerakan, yang biasanya dipakai pada sistem-sistem motion capture yang high-end atau kelas atas dan sangat mahal (Schimtz et al., 2013). Maka dari itu, sistem ini sering disebut pula dengan "markerless (based) motion-capture."

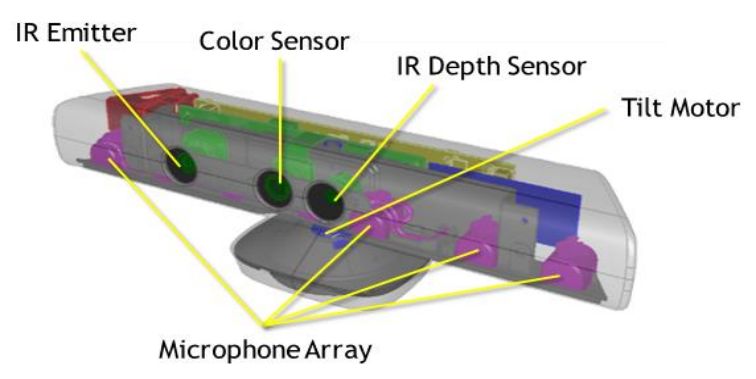

Gambar 1. Sensor-sendor pada Perangkat Kinect (Microsoft Library)

Teknologi Kinect sudah lama dipakai untuk motion capture terutama untuk skeletal (kerangka tulang manusia) dan facial (wajah) tracking. Motion capture yang paling sering dilakukan di sini adalah untuk keperluan video game, untuk merekam dan menganalisis pattern gerakan tubuh manusia. Kinect dianggap sangat akurat merekam gerakan tubuh manusia dengan perbedaan pada segmen tangan dan kaki (van Diest, et al., 2014). Namun begitu, penggunaan Kinect bagi orang awam masih belum banyak dipakai dan masih perlu diujicobakan lagi. Terutama saat ini di mana semua orang dapat dengan mudah membuat konten atau materi digital atau online. Dengan perkembangan kemudahan akses ke teknologi untuk pembuatan konten digital, sudah seharusnya teknologi motion capture dapat lebih dimanfaatkan lagi oleh 
pendidik dan kreator konten agar lebih mengaplikasikan animasi yang membuat proses penyampaiannya lebih efektif. Kurang-nya penggunaan teknologi Kinect lebih di-sebabkan karena masih belum ada panduan set-up yang memudahkan agar kita dapat melakukan sendiri, serta masih adanya pengaturanpengaturan lebih lanjut pada hardware, software, dan sistem komputer yang tidak langsung siap "out of the box."

Software lain yang akan dipakai adalah Blender versi 2.8, sebuah program 3D yang open source dan gratis sehingga tersedia untuk diunduh dan dipakai pada komputer. Program Blender mampu mengerjakan hampir seluruh pipeline 3D seperti modeling, rigging, animasi, simulasi, rendering, compositing, motion tracking, video editing, dan animasi $2 D$. Untuk kebutuhan percobaan ini, Blender dipakai untuk membentuk dan menggerakkan skeleton rigging manusia. Skeleton atau bone rig ini berbentuk seperti susunan tulang sederhana manusia, yang terdiri dari titik2 utama persendian manusia seperti leher, lengan, siku, tangan, pinggul, lutut, dan kaki (lihat Gambar 2).

Software selain Blender adalah NI Mate yang diperlukan untuk menterjemahkan data motion capture dari sensor Kinect secara realtime ke Blender. NI Mate akan berfungsi sebagai add-on dalam Blender. NI Mate juga tersedia versi yang gratis, sehingga masih mudah untuk diperoleh dan digunakan. Lalu format yang digunakan adalah OSC format, yang merupakan protokol untuk jaringan synthesizer suara, computer, dan perangkat multimedia lainnya, untuk keperluan seperti kinerja musik atau kontrol pertunjukan.

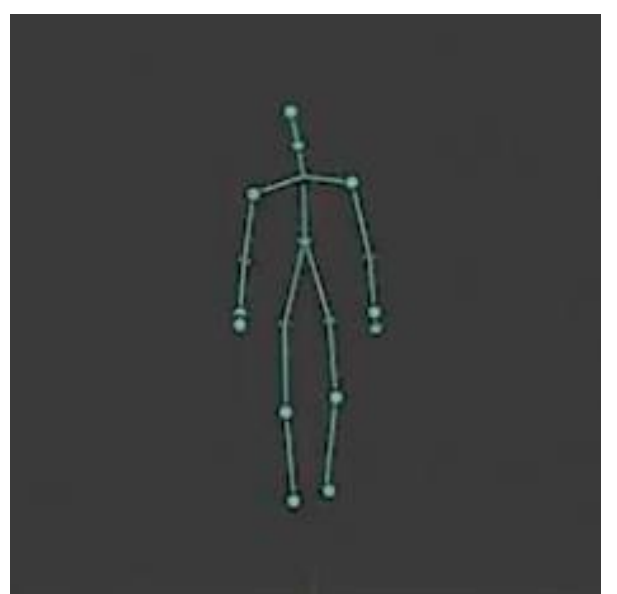

Gambar 2. Skeleton Rigging dalam Blender (dokumentasi pribadi)
Keseluruhan alat terhubung dan digunakan pada komputer gaming laptop standar dengan Intel processor i5. Alat-alat yang tercantum di sini memang bukan merupakan alat-alat yang masih tergolong umum. Maka dari itu tujuan dilakukan penelitian ini adalah mencarikan dan memberikan saran mengenai suatu sistem yang paling sederhana yang dapat digunakan oleh banyak pihak dalam menciptakan dan menggerakkan figur atau karakter animasi 3D secara mudah.

\section{Metode}

Metode yang digunakan adalah dengan mengujicobakan Kinect dengan aplikasi NI Mate dan Blender. Set up di dalam Blender menyusun rigging tulang manusia sederhana seperti pada Gambar 3. Rigging ini terdiri dari sendi-sendi utama pada beberapa "landmarks" manusia beserta tulang-tulang penghubungnya (bones). Selain itu, aplikasi NI Mate untuk membaca data dari Kinect diinstalasikan di dalam Blender sebagai add-on, sehingga dapat menggerakkan posisi titik-titik sendi pada skeleton rig.

Batasan yang kami tentukan adalah dari segi kemudahan mengakses atau mendapatkan alat tersebut dan yang paling sederhana atau mudah untuk dilakukan di lokasi dan situasi pada umumnya dalam ruangan di lokasi kampus atau rumah di Surabaya, tempat penelitian dilakukan.

Percobaan dilakukan dengan menginstalasi keseluruhan sistem dan melakukan rekam gerak pada sistem. Proses di awal mencobakan instalasi tersebut apakah sudah sesuai batasan yang ditentukan dan sudah bekerja sesuai fungsi yang diharapkan. Proses selanjutnya dilakukan percobaan terhadap gerakangerakan dasar manusia yang dapat direkam oleh sistem, dan bisa tidaknya sistem merekam secara baik atau tanpa kesalahan. Hasil dari proses rekaman kedua didokumentasikan secara tertulis dan rekaman video untuk kemudian dianalisis untuk dapat memberikan saran terbaik dalam penggunaan sistem Kinect ini. Analisis dilakukan dengan melihat hasil rekaman video gerakan yang telah didapatkan dan menentukan keberhasilan motion capture apakah berhasil merekam gerak dengan baik atau adakah hal yang keliru dalam motion capture tersebut, dan mencatatkan hal yang tidak benar. 


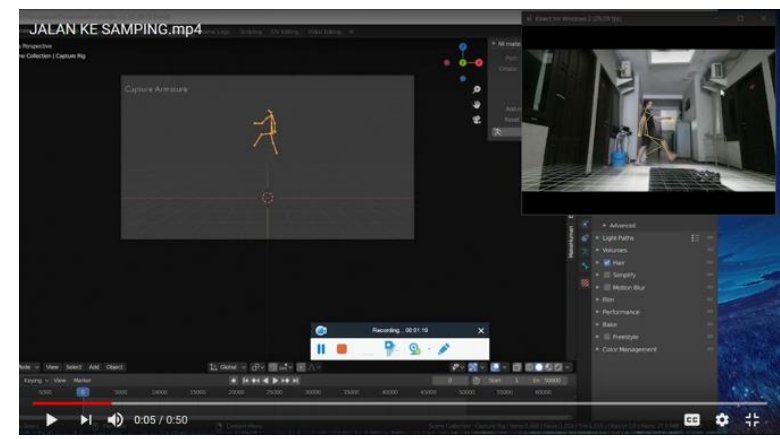

Gambar 3. Set up bone rigging dalam Blender Merespon Gerakan yang Diterima dari Sensor Kinect Secara Real-Time (dokumentasi pribadi)

\section{Hasil dan Diskusi}

Tahap awal percobaan adalah untuk menata alat-alat Kinect pada komputer dan menginstalasi NI Mate Motion Capture sebagai addon dalam Blender. Permasalahan yang ditemukan pada tahap awal selama pemakaian add-on NI Mate dalam Blender adalah:

1. Saat pertama kali menginstalasi aplikasi NI Mate, aplikasi terus-menerus mengalami crash. Terjadinya crash adalah ketika di saat menjalankan aplikasi kurang lebih 2 menit, aplikasi berhenti dan gagal terbuka. Telah ditemukan solusi menghindari crash ini dengan mengubah preferensi menghilangkan centang pada "Use GPU transfer".

2. Permasalahan kedua adalah add-on NI Mate di Blender menghasilkan gerakan tulang yang tidak mulus, berbeda saat melihat hasil gerakan langsung di aplikasi NI Mate.

3. Permasalahan ketiga adalah saat melakukan motion capture, tulang terkadang bisa hancur atau berantakan, terlepas dari posisi natural, secara tiba-tiba. Hal ini diasumsikan pengaruh kurang cahaya ketika melakukan record motion capture atau kurang compatible antara NI Mate dan Blender.

Dalam hal ini, di lain kesempatan dan akan dicobakan setting dengan software lain selain NI Mate. Selain NI Mate juga ada yang lain seperti dari iPi Mocap Studio dari iPi Soft. Namun agar percobaan dapat konsisten, saat ini difokuskan terlebih dahulu dengan program NI Mate.

Pada percobaan kedua motion capture menggunakan add-on NI Mate di Blender, ditemukan beberapa hal:
1. Permasalahan di bone kaki

Saat mencoba untuk merekam gerakan, bone/tulang kaki selalu rusak atau tidak beraturan, terkadang bahkan tidak dapat mengikuti gerakan kaki model. Sedangkan tulang paha sampai atas tidak mengalami masalah saat model bergerak dengan posisi badan lurus atau menghadap ke kamera. Bone juga ikut bergerak sesuai dengan gerakan model. Sedangkan jika posisi tubuh model menyamping, bone kaki pasti akan rusak, contohnya saat melakukan walk cycle, bone kaki menjadi tidak beraturan. Gerakan bone kaki dan tangan bisa tidak sesuai dengan gerakan kaki pada model. Permasalahan ini sering muncul ketika tubuh model sedang dalam posisi menyamping.

2. Bone tidak mampu mengikuti gerakan model yang cepat. Dalam percobaan sebelumnya, kami menyadari bahwa bone tidak dapat mengikuti dengan baik gerakan model jika model bergerak terlalu cepat. Permasalahan ini diperkirakan terletak pada fps-nya (frame per second). Dengan versi NI Mate gratis ini, peneliti hanya dapat menggunakan $30 \mathrm{fps}$, sedangkan dengan lisensi Pro yang berbayar, dapat menggunakan $60 \mathrm{fps}$.

Maka dari itu, setelah mencoba agar bone dapat bergerak sesuai dengan gerakan model, solusi yang ditemukan adalah gerakan model harus pelan, agar gerakan bone sesuai dengan gerakan model, serta tubuh model menghadap kamera agar bone tidak berantakan atau rusak.

3. Bone kaki (feet) dan tangan (hands) rusak

Dalam melakukan proses perekaman, bone telapak tangan dan telapak kaki pasti tidak sesuai dengan gerakan model, biarpun tubuh model sudah menghadap kamera, bone-nya tetap rusak. Akhirnya bone kaki dan tangan tersebut dihapus, kemudian menonaktifkan sensor pada bone tersebut di aplikasi NI Mate, dan hasilnya lebih baik dari sebelumnya saat masih ada bone telapak kaki dan telapak tangan.

Tabel 1 mendokumentasikan saat percobaan motion capture menggunakan Kinect, NI Mate, dan Blender, untuk gerakan-gerakan standar manusia. Dalam Tabel 1 dicatat jenis gerakan, tinggi telapak kaki, postur tubuh, arah tubuh, apakah baik atau kurang baik, serta masukan atau saran untuk memperbaiki. 
Tabel 1. Percobaan Motion Capture Gerakan-Gerakan Standar Manusia dengan Set-Up Kinect-NI Mate-Blender

\begin{tabular}{|c|c|c|c|c|c|c|}
\hline Gerakan & $\begin{array}{l}\text { Tinggi } \\
\text { Telapak } \\
\text { Kaki }\end{array}$ & $\begin{array}{l}\text { Postur } \\
\text { Tubuh } \\
\text { (Tegak, } \\
\text { Bungkuk) }\end{array}$ & \begin{tabular}{|} 
Arah Tubuh \\
(Depan, \\
Samping, \\
Membelakangi) \\
\end{tabular} & Baik & Kurang & $\begin{array}{l}\text { Masukan/ } \\
\text { Saran untuk } \\
\text { Memperbaiki }\end{array}$ \\
\hline $\begin{array}{l}\text { Lari di } \\
\text { tempat }\end{array}$ & $20+\mathrm{cm}$ & Tegak & Depan & $\sqrt{ }$ & $\sqrt{ }$ & $\begin{array}{l}\text { Secara keseluruhan, } \\
\text { gerakan sudah hampir } \\
\text { sama dengan gerakan } \\
\text { model, hanya saja } \\
\text { masalah terdapat pada telapak kaki } \\
\text { yang kadang tidak beraturan. }\end{array}$ \\
\hline Lari pelan & $20+\mathrm{cm}$ & Tegak & Depan & $\sqrt{ }$ & $\sqrt{ }$ & $\begin{array}{l}\text { Gerakan yang di rekam hampir } \\
\text { sama, masalahnya bone badan } \\
\text { seperti miring } \\
\text { sedikit. }\end{array}$ \\
\hline Lari sedang & $20+\mathrm{cm}$ & Tegak & Depan & $\sqrt{ }$ & $\sqrt{ }$ & $\begin{array}{l}\text { Gerakan bone dengan } \\
\text { gerakan model sama, } \\
\text { hanya telapak kaki yang terkadang } \\
\text { bisa berbeda sendiri. }\end{array}$ \\
\hline Lari cepat & $20+\mathrm{cm}$ & Tegak & Depan Samping & $\sqrt{ }$ & $\sqrt{ }$ & $\begin{array}{l}\text { Masalah-nya hampir sama seperti } \\
\text { saat melakukan lari sedang, tapi di } \\
\text { lari cepat ini, bone telapak kaki } \\
\text { tidak terlalu berubah jika depan, } \\
\text { tapi berma-salah jika dari samping }\end{array}$ \\
\hline $\begin{array}{l}\text { Jalan di } \\
\text { tempat }\end{array}$ & $20+\mathrm{cm}$ & Tegak & $\begin{array}{l}\text { Depan } \\
\text { Samping }\end{array}$ & $\sqrt{ }$ & $\sqrt{ }$ & $\begin{array}{l}\text { Bone telapak kaki } \\
\text { terkadang masih tidak } \\
\text { sama dengan gerakan } \\
\text { model. }\end{array}$ \\
\hline Jalan pelan & $20+\mathrm{cm}$ & Tegak & $\begin{array}{c}\text { Depan } \\
\text { Belakang }\end{array}$ & $\sqrt{ }$ & $\sqrt{ }$ & $\begin{array}{l}\text { Bone telapak kaki } \\
\text { terkadang tidak sama } \\
\text { dengan gerakan model. }\end{array}$ \\
\hline Jalan sedang & $20+\mathrm{cm}$ & Tegak & Depan & $\sqrt{ }$ & $\sqrt{ }$ & $\begin{array}{l}\text { Permasalahan sama } \\
\text { dengan jalan pelan dan sedang (saat } \\
\text { melangkah) }\end{array}$ \\
\hline Jalan cepat & $20+\mathrm{cm}$ & Tegak & Depan & $\sqrt{ }$ & $\sqrt{ }$ & $\begin{array}{l}\text { Permasalahan sama } \\
\text { dengan jalan pelan dan sedang (saat } \\
\text { melangkah) }\end{array}$ \\
\hline $\begin{array}{l}\text { Lambai } \\
\text { tangan, } \\
\text { mengangkat } \\
\text { barang }\end{array}$ & $20+\mathrm{cm}$ & Tegak & Depan Samping & $\sqrt{ }$ & - & $\begin{array}{l}\text { Gerakan sama persis } \\
\text { dengan gerakan model }\end{array}$ \\
\hline Lompat & $20+\mathrm{cm}$ & Tegak & Depan & $\sqrt{ }$ & - & $\begin{array}{l}\text { Gerakan sama persis } \\
\text { dengan gerakan model }\end{array}$ \\
\hline Dorong & $20+\mathrm{cm}$ & Bungkuk & Samping & $\sqrt{ }$ & $\sqrt{ }$ & $\begin{array}{l}\text { Bone tangan } \\
\text { terkadang masih tidak } \\
\text { sama dengan gerakan } \\
\text { model. }\end{array}$ \\
\hline $\begin{array}{l}\text { Aksi (berdiri } \\
\text { dan jongkok) } \\
\end{array}$ & $20+\mathrm{cm}$ & $\begin{array}{c}\text { Tegak } \\
\text { Bungkuk }\end{array}$ & $\begin{array}{c}\text { Depan } \\
\text { Samping }\end{array}$ & $\sqrt{ }$ & $\sqrt{ }$ & $\begin{array}{l}\text { Bone kaki terkadang masih tidak } \\
\text { sama dengan gerakan model }\end{array}$ \\
\hline \begin{tabular}{|l|} 
Aksi (dansa \\
dan berdiri \\
minum sambil \\
menelpon)
\end{tabular} & $20+\mathrm{cm}$ & Tegak & Depan & $\sqrt{ }$ & - & $\begin{array}{l}\text { Gerakan sama persis } \\
\text { dengan gerakan model }\end{array}$ \\
\hline
\end{tabular}

Dari hasil percobaan yang tertera pada Tabel 1, permasalahan yang didapat selama melakukan motion capture adalah bone telapak kaki, yang di setiap gerakan pasti ada sekali atau berkalikali tidak beraturan. Lalu untuk gerakan seperti lari ke samping, lompat, aksi, tidak dilakukan dengan berlebihan karena terbatas nya ruang dan lebar sudut pandang dari Kinect. Selain itu dari percobaan awal, NI Mate juga terbatas dalam memproses gerakan cepat. Maka dari itu perlu melakukan gerakangerakan yang tidak terlalu cepat. Kemudian, gerakan arah ke depan dan membelakangi, hasilnya akan sama. 

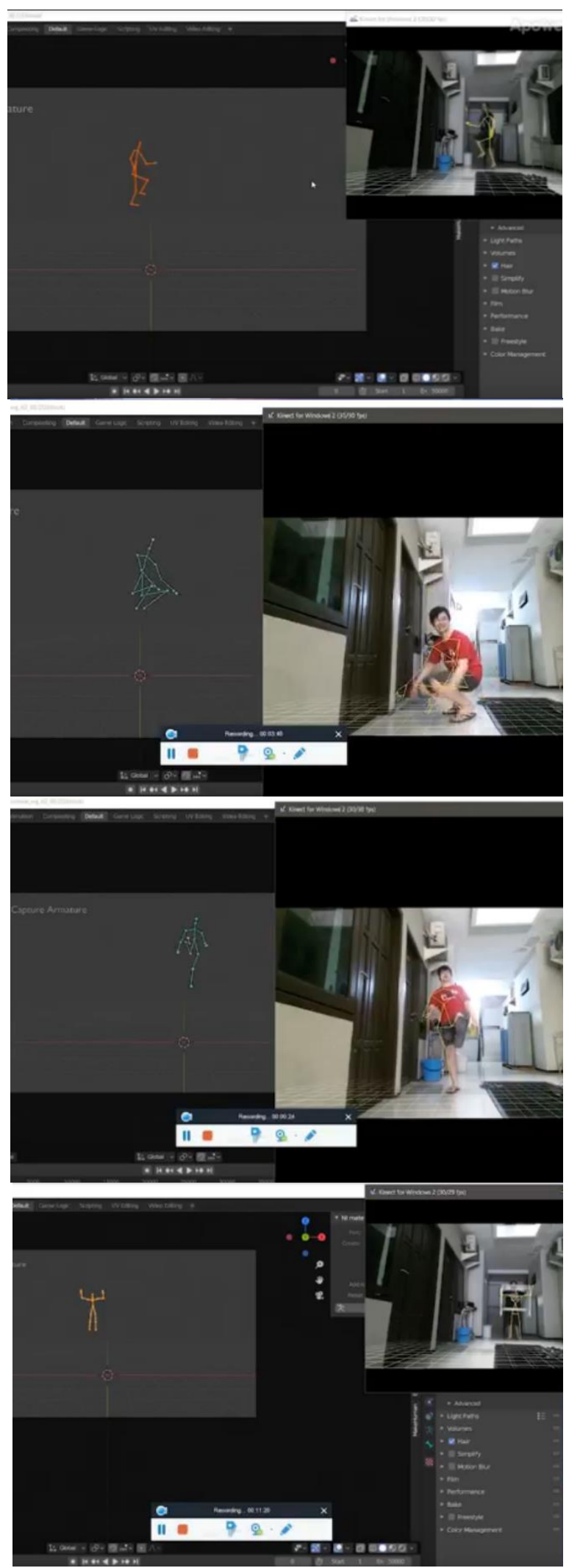

Gambar 4. Beberapa Rekaman Proses Uji Coba Gerakan (dokumentasi pribadi)

Dari hasil uji coba tersebut, permasalahan bone telapak kaki yang kadang berantakan, menurut dari hasil pengamatan setelah menonton ulang rekaman, mungkin pengaruh kulit telapak dan keramik lantai yang hampir sama, karena pengaruh cahaya, maka diperlukan pencahayaan yang terang.

Kinect hanya mampu mendeteksi model dengan jarak 2,5 sampai dengan 3 meter. Selebihnya, Kinect tidak dapat mendeteksi model. Jarak dan lebar pandang dari Kinect perlu dijaga, karena terbatas.

Kolom baik dan buruk diberi "ฟ", karena walaupun gerakan tersebut masih bisa terdeteksi, masih ada satu bagian yang sedikit bermasalah, seperti bone telapak kaki.

Semua proses perekaman motion capture telah di-screen record. Hasil dari percobaan dapat dinilai bahwa deteksi harus pada area yang terang dan longgar agar lebih efektif, akurasi masih kurang terutama pada telapak kaki dan telapak tangan, juga pada posisi miring ke samping, akurasi juga tidak baik pada gerakan yang terlalu cepat, namun masih perlu uji coba lebih lanjut untuk spesifikasi hardware dan software yang lebih tinggi (seperti pada fps). Persiapan untuk keseluruhan sistem set up software dan hardware perlu waktu untuk mencobakan terlebih dahulu.

\section{Simpulan}

Telah diketahui bahwa merekam gerak atau motion capture merupakan bagian dan salah satu teknik dari proses animasi yang penting untuk memperoleh sistem yang efisien dan mudah dalam menggerakkan karakter, baik secara real-time atau pun tidak. Telah diketahui pula bahwa Kinect yang merupakan alat pendekteksi gerakan adalah alat yang tidak mahal untuk 3D motion capture dibandingkan sistem sensor yang lain. Setelah melakukan percobaan menggunakan Kinect dan menilai potensinya untuk digunakan sebagai solusi low cost dan mudah bagi content creator yang awam, terutama untuk mereka dalam dunia pendidikan, dapat diberikan beberapa saran.

Set up Kinect-NI Mate-Blender merupakan penataan rangkaian sistem yang dapat dianjurkan yang paling mudah diakses saat ini. Ke depan tidak menutup kemungkinan ada alternatif lain yang dapat menggantikan. Set up rigging perlu pemahaman dasar pembuatan bones dalam program 3D Blender. Anjuran pembuatan bone ini adalah seperti pada Gambar 2, pada landmark utama persendian manusia namun tidak pada bone telapak kaki 
dan telapak tangan dimana akurasi motion capture Kinect di sini sering gagal merekam dengan baik. Dengan keterbatasan ini dapat dianjurkan pemakaian motion capture Kinect untuk animasi karakter digital 3D yang sederhana seperti boneka atau figur-figur sederhana lainnya yang tidak perlu menunjukkan detail tangan dan kaki.

Selain peniadaan tangan dan kaki, anjuran selanjutnya adalah untuk melakukan gerakan untuk motion capture dengan tidak terlalu cepat agar rekaman dapat dilakukan dengan baik. Gerakan juga terbatas pada ruangan dan jarak pandang yang dekat. Meskipun dengan keterbatasan-keterbatasan di atas, Kinect masih dapat disarankan sebagai solusi motion capture yang murah, mudah, dan cocok untuk animasi sederhana dengan karakter yang sederhana. Saran ke depan adalah untuk menentukan bentuk karakter sederhana seperti bagaimana yang cocok untuk digunakan dengan sistem ini.

\section{Daftar Pustaka}

Bilesan A., Konno, A., Behzadipour S., Tsujita, T., \& Komizunai, S. (2019). Markerless Human Motion Tacking Using Microsoft Kinect SDK and Inverse Kinematics. Research Gate Human motion capture project, June 2019. https://www.researchgate.net/publication/3 34049964

Dutta, T. (2012). Evaluation of the KinectTM Sensor for 3-D Kinematic Measurement in the Workplace. Applied Ergonomics, 43(4), 645-649.

https://doi.org/10.1016/j.apergo.2011.09.011

Microsoft. Kinect for Windows Sensor Components and Specifications. https://docs.microsoft.com/ en-us/previous-versions/windows/kinect1.8/jj131033(v=ieb.10)

Schmitz, A., Ye, M., Shapiro, R., Yang, R., \& Noehren, B. (2013). Accuracy and Repeatability of Joint Angles Measured Using A Single Camera Markerless Motion Capture System. Journal of Biomechanics, 47(2), 587-591. https://doi.org/10.1016/j.jbiomech.2013.11.0 31

van Diest ., Stegenga, J., Wörtche, H.J., Klaas, P., Gijsbertus J, V., Claudine J.C., L. (2014). Suitability of Kinect for Measuring Whole Body Movement Patterns During Exergaming. Journal of Biomechanics, 47(12), 2925-2932. https://doi.org/10.1016/j.jbiomech.2014.07.017

Vera, L., Gimeno, J., Coma, I., Fernandez, M. (2011). Augmented Mirror: Interactive Augmented Reality System Based on Kinect. LNCS 6949, 483-486.

Zhang, Z. (2012). Microsoft Kinect Sensor and Its Effect. IEEE MultiMedia, 19(2), pp. 4-10, https://doi.org/10.1109/MMUL.2012.24 